\title{
Screening for Postpartum Depression and Associated Factors among Women who Deliver at a University Hospital, Nepal. Kunwar D, ${ }^{1}$ Corey E K, ${ }^{2}$ Sharma $\mathrm{P}^{3}$ Risal $\mathrm{A}^{1}$
}

${ }^{1}$ Department of Psychiatry

Dhulikhel Hospital, Kathmandu University School of Medical Sciences (KUSMS),

Dhulikhel, Kavre, Nepal

${ }^{2}$ Global health institute,

University of Wisconsin-Madison, USA

${ }^{3}$ Medical Officer, Mental Disease Treatment and Rehabilitation Centre

Attarkhel, Kathmandu

\section{Corresponding Author}

Dipak Kunwar

Department of Psychiatry

Dhulikhel Hospital, Kathmandu University School of Medical Sciences (KUSMS)

Dhulikhel, Kavre, Nepal

E-mail: seetal501@hotmail.com

\section{Citation}

Kunwar D, Corey E K, Sharma P, Risal A. Screening for Postpartum Depression and Associated Factors among Women who Deliver at a University Hospital, Nepal. Kathmandu Univ Med J 2015;49(1):44-8.

\section{ABSTRACT}

\section{Background}

Postpartum depression (PPD) is a neglected area of maternal health care in developing countries like Nepal; not only in the treatment aspect, but also, in the areas of research. However, it is important to identify and treat postpartum depression because it can have grave consequences for both the mother and her children.

\section{Objective}

To determine the screening prevalence and risk factors of postpartum depression, among women who deliver at university hospital Nepal.

\section{Method}

This is a cross-sectional study investigating the relationship between postpartum depression and various factors. A total of 100 postpartum women who presented to a Dhulikhel hospital for delivery were interviewed on days 2-3 after delivery. The mothers were administered Edinburgh Postnatal Depression Scale (EPDS) as well as a proforma that included questions about the known risk factors (sociodemographic and sociocultural factors, and mother-related, pregnancy-related, and child related factors).

\section{Result}

The overall screening prevalence of depressive symptoms in the postnatal period (defined as EPDS=>13) was $29 \%(95 \% \mathrm{Cl} 20.1 \%-37.8 \%)$. On univariate analysis (chi square test), postpartum depression was significantly associated with pregnancy complications $(p<0.01)$, infant's health problems $(p<0.001)$ and vaginal delivery $(p$ $<0.05)$.

\section{Conclusion}

Postpartum depression is common among Nepalese women and can be detected early in the postpartum periods; and many psychosocial factors like pregnancy complications, infant's health problems and vaginal delivery are associated with it. It is recommended that mothers with high risk should be routinely screened for postpartum depression.

\section{KEY WORDS}

Developing countries, hospital delivery, infant welfare, prevalence, risk factors 


\section{INTRODUCTION}

Postpartum depression (PPD) is a neglected area of maternal healthcare in developing countries.

It is important to identify and to treat PPD because it can negatively affect maternal parenting ability and infant cognition. ${ }^{1}$ Infants born to mothers with PPD have been shown to have lower cognitive functioning, adverse emotional development, problematic sleep habits, lower preventive health care utilization, , behavior problems, higher risk for anxiety, disruptive and affective disorder, decreased breastfeeding and worse nutritional outcomes. ${ }^{2}$ Women in western countries develop significant depression in the months following childbirth. ${ }^{3}$

Information on PPD in developing countries is limited. ${ }^{4,5}$ In Nepal, one study measured the prevalence of PPD in the Lalitpur district. ${ }^{3}$ They measured the rate of depressive symptoms in a clinical, a rural, and an urban population. They found that the overall prevalence of depressive symptoms was $4.9 \%$ and that there was no significant difference in depression levels among the 3 populations of women. ${ }^{6}$ When they determined the factors associated with PPD they concluded that depression (EPDS >12) was positively associated with the husband's alcoholism, polygamy, previous depression, stressful life events, multiparity, smoking and depression during pregnancy. ${ }^{7}$ There have been a limited number of studies on postpartum depression in Nepal. So, it would be meaningful and useful to continue researching this important topic in this country.

\section{METHODS}

\section{Ethical approval}

The study was initiated after receiving approval from the Institutional Review Committee (IRC), Kathmandu University School of Medical Sciences (KUSMS). Informed consent was obtained from all study participants.

\section{Study design and setting}

This is a Descriptive cross-sectional study of postpartum women who received antenatal and postnatal care at Dhulikhel Hospital, Kathmandu University Hospital situated in Dhulikhel municipality of the Kavre District.

\section{Study population, sampling and recruitment}

All eligible participants, who delivered at Dhulikhel hospital and who were 2-3 days Postpartum during our study period from $15^{\text {th }}$ March to $15^{\text {th }}$ April 2014 were included in the study.

Excluded were women who were unwell due to perinatal medical complications, had a pre-existing chronic physical and mental illnesses and who were unable to give informed consent.
Hence, total subjects were 100 (using convenience method of sampling)

During the 1-month study period, the authors went daily to the postpartum ward and approached the eligible women. Participants, who fulfilled the inclusion criteria for the study, were provided written informed consent.

\section{Instruments:}

\section{Proforma:}

We designed a questionnaire focusing on sociodemographics and known psychosocial risk factors for postpartum depression. The questions concerned: age, marital status, occupation, religion, ethnicity/caste, sick leave during pregnancy, highest educational level, family income, number of pregnancies, if she is breastfeeding or not, whether underwent vaginal delivery or cesarean section, support from family, support from partner, whether the pregnancy was planned, any health problems of the infant, problems with the pregnancy, number of prenatal care visits, personal history of depression or bipolar disorder, partner history of depression, psychiatric history in immediate family, and life stressor.

\section{The Edinburgh Postnatal Depression Scale (EPDS):}

The EPDS is a 10-item self-rating questionnaire that was developed in Edinburgh by Cox and colleagues to screen for depression in the postnatal period. ${ }^{8}$ Each question has four alternative answers, scoring $0-3$, giving a maximum total score of 30 . The questionnaire has subsequently been validated and used in many cultures and languages, ${ }^{9}$ including Nepal. ${ }^{10}$ The cut-off scores for detecting major depression varied from 9 or 10 to 12 or 13 . The sensitivity and specificity estimates also varied (from $65 \%$ to $100 \%$ and from $49 \%$ to $100 \%$, respectively). A further validation study yielded similar results. ${ }^{11}$

\section{Data analysis}

The data was analyzed using the SPSS version 16.0 (SPSS Inc.,Chicago, IL). Descriptive Statistics (including means, standard deviations, frequencies and percentage) were calculated for the sociodemographic, obstetric, and psychosocial variables. Chi square test was applied for association of postpartum depression with different variables.

\section{RESULTS}

\section{Participant characteristics}

A total of 100 women fulfilled the inclusion criteria for the study, and were included in the analysis. Association of postnatal depression with sociodemographic variables are depicted in Table 1 and association of obstetric and infant characteristics of the study sample are depicted in table 2 . 
Table 1. Association of sociodemographic variables with postpartum Depression

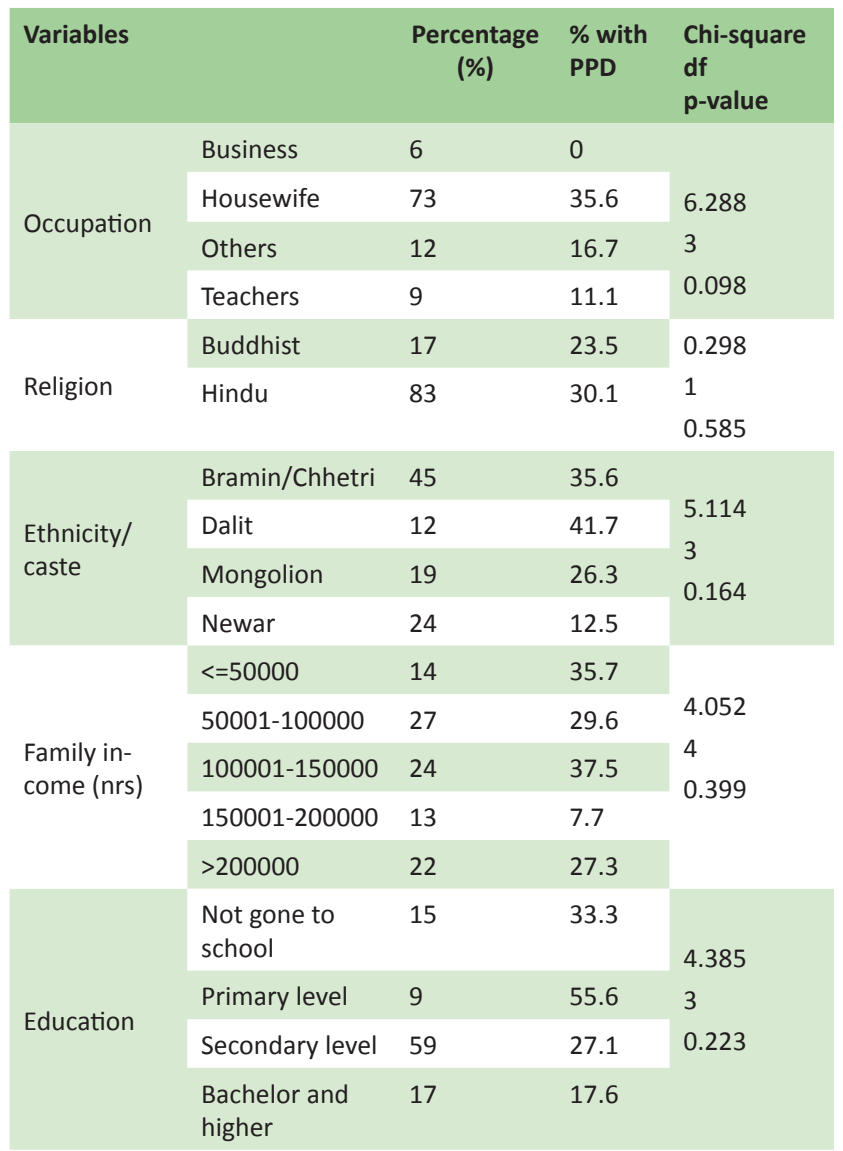

The mean age of the sample was 24.52 years $( \pm 4.18)$. Majority of them (59\%) women had secondary level education while $15 \%$ never attended school. All of them were married. Most women were Hindus (83\%), housewives (73\%), belonging to the Bramin/Chhettri (45\%) and $27 \%$ of households had an average family income from 50000-100000 Nepalese Rupees per year. (Table 1)

Most pregnancies were planned (74\%) and almost onethirds were primigravid and a majority of women (93\%) did not have any issues regarding their infant's health. More than two-thirds of the women had vaginal delivery (68\%). almost all women (91\%) had no pregnancy problems and 79\% had no miscarriages (Table 2).

None of these socio-demographic variables were statistically significant in relation to the postnatal depression (EPDS $>13)$.

\section{Prevalence of postpartum depression}

The screening prevalence of depression was $29 \%$ ( EPDS score $>13$ ) and mean EPDS score was 10.29(SD \pm 4.02 ).

\section{Factors associated with postpartum depression}

The factors associated with postpartum depression are shown in table 2 .
Table 2. Association of obstetric and infant characteristics with postpartum Depression

\begin{tabular}{|c|c|c|c|c|}
\hline Variables & & Frequency & $\begin{array}{l}\text { \% with } \\
\text { PPD }\end{array}$ & $\begin{array}{l}\text { Chi-square } \\
\text { df } \\
\text { p-value }\end{array}$ \\
\hline \multirow[b]{2}{*}{ First child } & No & 39 & 30.8 & \multirow{2}{*}{$\begin{array}{l}0.097 \\
1 \\
0.755\end{array}$} \\
\hline & Yes & 61 & 27.9 & \\
\hline \multirow{3}{*}{ Miscarriage } & No & 79 & 27.8 & \multirow{3}{*}{$\begin{array}{l}2.131 \\
2 \\
0.345\end{array}$} \\
\hline & One & 18 & 38.9 & \\
\hline & Two or more & 3 & 0 & \\
\hline \multirow{2}{*}{$\begin{array}{l}\text { Vaginal } \\
\text { delivery/ } \\
\text { c-section }\end{array}$} & C-section & 32 & 15.6 & \multirow{2}{*}{$\begin{array}{l}4.089 \\
1 \\
0.043^{*}\end{array}$} \\
\hline & Vaginal & 68 & 35.3 & \\
\hline \multirow{2}{*}{$\begin{array}{l}\text { Planned } \\
\text { pregnancy }\end{array}$} & No & 26 & 38.5 & \multirow{2}{*}{$\begin{array}{l}1.528 \\
1 \\
0.216\end{array}$} \\
\hline & Yes & 74 & 25.7 & \\
\hline \multirow{2}{*}{$\begin{array}{l}\text { Infant health } \\
\text { problem }\end{array}$} & No & 93 & 23.7 & \multirow{2}{*}{$\begin{array}{l}18.428 \\
1 \\
0.000 * * *\end{array}$} \\
\hline & Yes & 7 & 100 & \\
\hline \multirow{2}{*}{$\begin{array}{l}\text { Pregnancy } \\
\text { problem }\end{array}$} & No & 91 & 24.2 & \multirow{2}{*}{$\begin{array}{l}11.428 \\
1 \\
0.001 * *\end{array}$} \\
\hline & Yes & 9 & 77.8 & \\
\hline
\end{tabular}

${ }^{*} p<0.05, * * p<0.01, * * * p<0.001$

Factors found to be significantly associated with increased risk of depression were vaginal delivery $(P<0.05)$, pregnancy problems $(P<0.01)$ and infants health problem $(p<0.001)$.

\section{DISCUSSION}

The prevalence of depressive symptoms in the postnatal period found in this study was $29 \%$. This was higher than the level reported in previous studies conducted in Nepal: that reported the prevalence ranging between 5 to $12 \%{ }^{6,10}$

Studies from other neighboring countries have documented postpartum depression prevalence rates of $11 \%$ (China), ${ }^{12}$ $40 \%$ (Pakistan), ${ }^{13}$ and ranging from 11 to $23 \%$ ( India). ${ }^{14-17}$

The prevalence of postpartum depression (PPD) is currently considered to be $10-15 \%$. However, there is a wide range of reported prevalence of PPD ranging from almost $0 \%$ to almost $60 \%$. And widely cited mean prevalence of PPD-10$15 \%$ is not representative of the actual global prevalence and magnitude of the problem, due to the wide range of reports. ${ }^{18}$

In contrast to the above mentioned studies, we did not find any significant association of postpartum depression with sociodemographic factors like age, occupation, religion, ethnicity education, or economy conditions.

There were also no significant association seen with psychosocial factors such as stressors, unplanned pregnancy, social support, husband's alcoholism, polygamy and previous depression. However, psychosocial factors, 
especially stress and social support are well documented predictors of postpartum depression. ${ }^{19-21}$ but one study from Nepal reported postpartum depression strongly associated with husband's alcoholism, polygamy and previous depression. $^{7}$

However, our study found significant association between vaginal deliveries, infant's health problems and pregnancy problems.

\section{Vaginal delivery}

We found high frequency of vaginal delivery compared to cesarean sections in our sample (68\% vs. $32 \%)$. Women who delivered vaginally had a significantly higher risk of postpartum depression than those giving birth by cesarean sections. This finding could not be compared to any other study from Nepal because of scarcity of literature. Internationally there are mixed results. A case control study from Armenia reported that the risk of PPD at the age of less than 25 years increased only among those who delivered their child through cesarean sections. ${ }^{22}$

In one meta-analysis, twenty four studies have been reviewed among them five studies showed significant adverse associations between postpartum depression and cesarean sections, 15 showed no significant association, and four found mixed results. They concluded that the largest and most methodologically sound studies have not been able to show an association. ${ }^{23}$

\section{Pregnancy complications}

Complications during pregnancy were significantly associated with postpartum depression in our sample. Our findings were in accordance with large Dutch study of 4,941 women which showed that various pregnancy and delivery complications predicted postpartum depression in women.

In that study, the risk of postpartum depression increased with an increasing number of complications. ${ }^{24}$ Another study from Japan also found postpartum depression was significantly associated with premature delivery and difficult labor. ${ }^{25}$

\section{REFERENCES}

1. Stein A, Gath DB, Bucher J, et al. The relationship between postnatal depression and mother-child interaction. Br. J Psychiatry 1991;158:46.

2. Beck CT. The effects of postpartum depression on child development: a meta-analysis. Arch Psychiatric Nurse 1998;12:12.

3. Murray L, Cooper P J. The impact of postpartum depression on child development. International Review of Psychiatry 1996; 8(1): 55-63.

4. Cox J L. Postnatal depression: a comparison of African and Scottish women. Social Psychiatry 1983;18:25-8.

5. Cooper P J, Tomlinson M, Swartz L, Woolgar M, Murray L, Molteno C. Post-partum depression and the mother-infant relationship in a South African peri-urban settlement. Br. J Psychiatry 1999; 175:554-8.

\section{Infant's health problems}

Regarding the association between postpartum depression and infant's related health problems, several studies have been reported: taking an infant to a primary care or an emergency department, ${ }^{26}$ premature infants, ${ }^{27,28}$ infant temperament or behavior, ${ }^{29-31}$ and infant sleep problems. ${ }^{32}$ We did not evaluate them individually all those infantrelated health problems. However, from our study, overall infant's health problems, especially when it required either outpatient treatment or hospitalization, seemed to be an important related factor which is consistent with review article on risk factors associated to post-partum depression in Asia.

One of our explanatory hypotheses is that caring for sick infants most likely puts an extra psychological burden on mothers. It would not be surprising that such problems provoked an onset of postpartum depression. ${ }^{33}$

The present study has several limitations. First, the study was conducted in a university hospital and mothers presented to our hospital were only included so, generalization of the results is not possible.

For diagnosis of depression, an elevated EPDS score should be followed by an interview. However, we used EPDS score solitarily because no participants were available for interview.

As the psychometric properties of the Nepali version of the EPDS have been shown to be satisfactory, also when interviews were not used, we can approve such screening scores to predict the prevalence of PPD in our study. ${ }^{34}$

\section{CONCLUSIONS}

Postpartum depression is highly prevalent in Nepal and there are several associated risk factors.

It is likely that interplay of these risk factors play a role in the causation of postpartum depression. Mental health screening and interventions should be integrated into existing maternal and child health programs. Further prevalence studies should be conducted in various settings in Nepal.
6. Ho-Yen, SD, Bondevik GT, Eberhard-Gran M, and Bjorvtn B. The prevalence of depressive symptoms in the postnatal period in Lalitpur district. Nepal. Acta Obstretriciaet Gynecologica. 2006;85: 1186-92.

7. Ho-Yen, SD, Bondevik GT, Eberhard-Gran M, and Bjorvtn B. Factors associated with depressive symptoms among postnatal women in Nepal. Acta ObstetriciaetGynecologica. 2007;86:291-297.

8. Cox JL, Holden JM, Sagovsky R. Detection of postnatal depression. Development of the 10-item Edinburgh Postnatal Depression Scale. Br J Psychiatry. 1987;150:782-6.

9. Eberhard-Gran M, Eskild A, Tambs K, Opjordsmoen S, Samuelsen SO. Review of validation studies of the Edinburgh Postnatal Depression Scale. Acta Psychiatr Scand. 2001;104:243-9. 
10. Regmi S, Sligl W, Carter D, Grut W, Seear M. A controlled study of postpartum depression among Nepalese women: validation of the Edinburgh Postpartum Depression Scale in Kathmandu. Trop Med Int Health 2002; 7:378-82.

11. Leverton TJ, Elliot SA. Is the EPDS a magic wand?: a comparison of the Edinburgh Postnatal Depression Scale and Health Visitor Report as predictors of di agnosis on the Present State Examination. J Reprod Infant Psychol 2000;4:279-96.

12. Lee $D$, Yip A, Chiu H, Leung $T$, Chung $T$. A psychiatric epidemiological study of postpartum Chinese women. Am J Psychiatry 2001;158: 220-6.

13. Rahman A, Lovel H, Bunn J, Iqbal Z, Harrington R. Mother's mental health and infant growth: a case-control study from Rawalpindi, Pakistan. Child Care Health Dev 2004; 30: 21-7

14. Savarimuthu R J, Ezhilarasu $P$, Charles $H$, Antonisamy B, Kurian $S$, et al. Post-partum depression in the community: a qualitative study from rural South India. Int J Soc Psychiatry 2010; 56: 94-102.

15. Anoop S, Saravanan B, Joseph A, Cherian A, Jacob K S. Maternal depression and low maternal intelligence as risk factors for malnutrition in children: a community based case-control study from South India. Arch Dis Child 2004; 89:325-9.

16. Patel V, Rodrigues M, DeSouza N.Gender, poverty, and postnatal depression: a study of mothers in Goa, India. Am J Psychiatry 2002; 159: 43-7.

17. Chandran M, Tharyan P, Muliyil J, Abraham S. Post-partum depression in a cohort of women from a rural area of Tamil Nadu, India. Incidence and risk factors. Br J Psychiatry 2002; 181: 499-504.

18. Halbreich, U, Karkun, S. Cross-cultural and social diversity of prevalence of postpartum depression and depressive symptoms. Journal of Affective Disorders 2006; 91: 97-111.

19. Pearlstein T, Howard M, Salisbury A, Zlotnick C. Postpartum depression. Am J Obstet Gynecol 2009; 200: 357-64.

20. Robertson E, Grace S, Wallington T, Stewart DE. Antenatal risk factors for postpartum depression: a synthesis of recent literature. Gen Hosp Psychiatry 2004; 26: 289-295.

21. O'Hara MW, Swain AM. Rates and risk of postpartum depression - a meta-analysis. Int Rev Psychiatry. 1996;8(1):37-54.
22. Petrosyan D, Armenian HK, Arzoumanian K. Interaction of maternal age and mode of delivery in the development of postpartum depression in Yerevan, Armenia. J Affect Disord 2011;135:77-81.

23. Carter FA, Frampton CM, Mulder RT. Cesarean section and postpartum depression: a review of the evidence examining the link. Psychosom Med. 2006;68(2):321-30.

24. Blom EA, Jansen PW, Verhulst FC, et al. Perinatal complications increase the risk of postpartum depression. The Generation R Study. BJOG 2010; 117(11):1390-8.

25. Tamaki R, Murata M, Okano T. Risk factors for postpartum depression in Japan. Psychiatry Clin Neurosci 1997;51(3):93-8.

26. Mandl KD, Tronick EZ, Brennan TA, Alpert HR, Homer CJ. Infant health care use and maternal depression. Arch Pediatr Adolesc Med. 1999; 153: 808-813.

27. Davis L, Edwards H, Mohay H, Wollin J. The impact of very premature birth on the psychological health of mothers. Early Hum. Dev. 2003;73:61-70.

28. Beck CT. Recognizing and screening for postpartum depression in mothers of NICU infants. Adv. Neonatal Care 2003;3:37-46.

29. Hopkins J, Campbell SB, Marcus M. Role of infant related stressors in postpartum depression. J. Abnorm. Psychol. 1987;96:237-41

30. Cutrona CE, Troutman BR. Social support, infant temperament, and parenting self-efficacy: A meditational model of postpartum depression. Child. Dev. 1986;57:1507-18.

31. Miller AR, Barr RG, Eaton WO. Crying and motor behavior of six-weekold infants and postpartum maternal mood. Pediatrics 1993;92: 551-558.

32. Hiscock $H$, Wake M. Infant sleep problems and postnatal depression: A community-based study. Pediatrics 2001; 107: 1317-22.

33. Ueda M, Yamashita $H$, Yoshida K. Impact of infant health problems on postnatal depression: Pilot study to evaluate a health visiting system. Psychiatry and Clinical Neurosciences 2006; 60(2):182-9.

34. Nepal MK, Sharma VD, Koirala NR, Khalid A, Shresta P. Validation of the Nepalese Version of Edinburgh Postnatal Depression Scale in tertiary health care facilities in Nepal. Nep J Psychiatry. 1999; 1:46-50. 